Saudi Journal of Business and Management Studies Abbreviated Key Title: Saudi J Bus Manag Stud ISSN 2415-6663 (Print) |ISSN 2415-6671 (Online) Scholars Middle East Publishers, Dubai, United Arab Emirates Journal homepage: https://saudijournals.com/sibms

Original Research Article

\title{
A Study on the Role of Advertising in Competitive Advantage and Brand Popularity (Case Study: Samsung Company)
}

\author{
Danial Shahrabi Farahani ${ }^{1 *}$, Abolghasem Ebrahimi ${ }^{2}$, Mohsen Moradian ${ }^{3}$, Mohammadreza Khani Tafti ${ }^{4}$ \\ ${ }^{1}$ University of Tehran, Tehran, Iran \\ ${ }^{2}$ Faculty of Economics, Management, and social sciences, Shiraz University, Shiraz, Iran \\ ${ }^{3}$ Faculty of Economics and Administrative Sciences, Babolsar, Mazandaran, University of Mazandaran, Iran \\ ${ }^{4}$ Faculty of Humanities and Social Sciences, University of Yazd, Yazd, Iran
}

DOI: $10.36348 /$ sjbms.2020.v05i04.002 $\quad$ | Received: 03.04.2020 | Accepted: 11.04 .2020 | Published: 17.04 .2020

*Corresponding author: Danial Shahrabi Farahani

\section{Abstract}

The purpose of this study was to review the role of advertising in competitive advantage and brand popularity of business enterprises in general (Samsung Company in Tehran). To this end, 278 managers at Samsung Company dealerships in Tehran were considered as the statistical sample. To collect data, a 57-item researcher-made questionnaire was used who's face and content validity criteria were approved by 30 experts. The reliability of the questionnaire was assessed through a preliminary test given to 30 subjects and the obtained figure came to more than 0.7 for all the examined variables, which is an acceptable level. For data analysis, descriptive statistics method in SPSS software, version 24, and the inferential statistics method and the structural equation modeling in the LISREL software, version 8, were used. Findings of the structural equation modeling indicated that advertising had a direct and positive effect on both the competitive advantage and the brand popularity of Samsung Company, in a way that a oneunit increase in advertising raises the competitive advantage and brand popularity of Samsung Company by 0.60 and 0.51 units, respectively.

Keywords: Advertising, Competitive Advantage, Brand Popularity, Business Enterprises.

Copyright @ 2020: This is an open-access article distributed under the terms of the Creative Commons Attribution license which permits unrestricted use, distribution, and reproduction in any medium for non-commercial use (NonCommercial, or CC-BY-NC) provided the original author and source are credited.

\section{INTRODUCTION}

Today, advertising and information dissemination in businesses have become an integral part of the economic firm in a manner that the sustainability of any business depends to a large extent on the success or failure of their information channels, marketing, market making, and advertising activities. In marketing, changing the consumers' attitude through inspiration by communication patterns is targeted. Marketing communication is very dynamic. The ability of marketing messages to change the views of consumers depends on the validity, attractiveness, and configuration of the message as well as on how to communicate it. Since the business environment is accompanied by increasing complexity, quick changes, and unex-pected developments in the markets, the selection of a target market is the basis for business positioning to meet the customers' needs and achieve the primary goals [1].

Effective promotional advertising does a set of actions in the form of various models of integrated marketing communication in order to communicate with the desired sectors in the target market and to impress them for the better positioning of products and services. On this basis, effective promotional advertising plays a pivotal role in advancing the company's marketing strategies and policies. Thus, elements of the promotion mix, on top of coordination with each other as well as the diverse needs of selected target markets, should be consistent and in line with the other components of the firm's marketing plan. Advertising is one of the essential communication tools in business [2]. The level of excitement used in advertising, type of product category in terms of mental 
conflict with the product, and functionality or pleasureorientation of the product can be considered as effective factors on consumer attitude [3]. Advertising is one of the vastest areas of marketing. In the public mind, the word "advertising" has come to be synonymous with the word "marketing". Advertising is in fact a social phenomenon, taken from a social need and containing a social purpose [4]. Every day there is a lot of advertising done by companies, which has caused the impact of advertising on consumer response to even decrease as consumers focus on advertising on a selective basis. Advertising is both a science and an art, which has expanded to have a special place not only in economics and business but also in many other sciences and concepts. Marketers use advertising to raise awareness and competitive advantage, and to ultimately choose a brand name. Advertising has always been considered a common and useful factor in terms of brand equity [5]. The intangible property of services has driven the organization towards promoting the brand position in the eye of the customers and creating brand popularity.

\section{THEORETICAL BACKGROUND}

In the era of technology and supply of goods and services, applying the right management techniques to marketing and advertising is very important to succeed among commercial competitors. Com-mercial advertising is one of the factors behind the success of a product or service. As companies are looking for new markets to sell their products in different parts of the world, they need to advertise their goods in these areas [1].

Advertising is in fact a type of communication that can even affect the social and cultural structure and make people closer or farther away from each other. Advertising has always been regarded as one of the essential communication tools in marketing activities and played a critical role in creating the right image of the brand in the minds of customers [2]. Research shows that advertising can affect all aspects of brand equity. The goal of many upgrading and promotional activities is motivating as well as influencing purchase and consumer behavior, which triggers a quick response and enhances sales. Given the hierarchy of effects, it may be concluded that advertising is related to brand loyalty and popularity. Numerous surveys strengthen the existence of attitudes towards the brand [5]. Marketing policies including promotions and public relations have positive effects on brand equity.

Researchers, by examining samples of students in American universities, have realized that a brand with a higher advertising budget has a higher level of value within itself. A positive emotional response to an advertisement has a direct relationship with brand recognition, a positive attitude towards it, and the customers' buying goals. Advertising is useful in creating awareness as well as a positive attitude for the brand, which can affect the feelings of customers. Emotion plays a major role in consumer decisionmaking and response and has a profound impact on customer reactions [6]. It is believed that stimulation of emotions is effective on perceived feelings and positive consumer attitudes towards advertising and brand [7].

Daniel Starch was a pioneer of advertising theory in the $20^{\text {th }}$ century. He defines advertising as "to motivate people towards a product or service, by providing information or creating a positive feeling, beyond what attracts the attention of the individual". Advertising is an indirect method to attract a potential customer to a product or a service. This act of motivating is realized via providing information, aimed at creating a favorable feeling; a concept referred to as a positive attitude towards the brand [8].

Advertising is believed to be a deliberate effort by some individuals or groups to control, shape, or change the attitudes of others utilizing communication tools, all with the aim of influencing their reaction to a particular situation in a way desirable to advertising planners. Advertising is an attempt to influence others, persuade them, and change their views on specific issues $[9,10]$.

Advertising is the monetary form of communication although some types of advertising, such as public services, use time and space assigned specifically to them. A message is sent through different types of mass media and reaches a wide range of potential consumers. Since advertising is a form of mass com-munication, it is impersonal. Therefore, a good definition of advertising will include all those attributes [11].

If the ultimate goal of advertising is to form a positive attitude towards the brand, increase in the likelihood of buying and a positive emotional response to advertising are considered as the consumer response. Studies show that consumer attitude towards advertising is positively related to the view and understanding of the brand and the purchase intention. The customer's ability to recall a brand results from effective advertising. Perceptual and cognitive models show that brand recognition resulting from a positive attitude towards the brand influences consumer responses and buying decisions [12]. Advertising is an attempt to create an indirect two-way communication system with the audience. The effects of advertising on the audiences can be summarized as follows [12,13]: raising awareness, creating a positive attitude, creating identity for the brand, product positioning in the market, maintaining relations, persuasion, and responding to competitors' activities.

On the other side of the spectrum, the competitive advantage is also a most critical issue in strategic management and marketing literature. 
Different perspectives exist regarding its determinants but the theorists in industrial organizations consider the environmental factors dominant. The first theorist to consider is Bain, who expressed his theory in 1968. The famous one among all is Michael Porter. According to his model, the purpose of an industrial unit is to analyze the industry. If the strategy causes the organization to fulfill its activities in a different and distinct manner from that of the competitors, the competency base facilitates the selection of diversity and differentiation which in turn gains a competitive advantage for the organization [14].

The company's profitability depends on the degree of adaptability between the strategic assets and the industry factors. Therefore, the competitive advantage is based on the interaction between the industrial organization and the theory of competency. In contrast, some theorists emphasize the importance of intra-organizational factors in gaining competitive advantage among which the resource-based view and the dynamic capability view are to be noted. In general, it can be said that based on environmental perceptions, the analysis unit is the industry while according to the resource-based and dynamic capability views as well as the competency-based theories, the unit of analysis is the organization [15]. Some useful definitions of competitive advantage are as follows [16]:

- Competitive advantage refers to the level of attractiveness of a company's sug-gestions from the customers' viewpoints as compared to those of the rivals.

- Competitive advantage is the distinction in the characteristics or dimensions of each company.

- Competitive advantage is the value that the organization offers its customers when such value is not offered by potential and actual competitors at the time.

Accordingly, the concept of competitive advantage has a direct relationship with the customer's desired values. Two important dimensions of competitive advantage include: creating and gaining a competitive advantage through efficient integration of environmental and organiza-tional resources, using networking and intelligence capabilities; and stabilizing the obtained competitive advantage with a view to its imitability as in the resource-based view. The more causally ambiguous the competitive advantage resources, the more socially complicated its productions and relations, making imitability difficult in turn [17].

Competition takes place on a global level today. Globalization increasingly collapses the supportive walls countries used to build around their national industries. Those countries and companies that are able to take advantage of global market opportunities may manage to create a competitive advantage. Japan is a good example of high motivation and competition in the domestic environment, which in turn have become the main reasons for its success in global competition [14]. Based on the concepts of strategic management, the competitive power of any organization is to a great extent influenced by factors of farther environments including the economic, political, social, tech-nological, and legal as well as the industrial environments. To define a theoretical model for the illustration of success in various industries and organizations in a highly competitive global environment, Michael Porter explains that the competitive advantage is achieved not only within the boundaries of industries and organizations but also from the environmental situation where those industries and organizations are located. He refers to four determinants of global competition as follows: 1) factor conditions; 2) demand conditions; 3) related and supporting industries; and 4) firm strategy, structure, and rivalry [18].

A review of industries all over the world indicates that Japan owns a competitive advantage in the automotive and consumer electronics industries, Germany in the chemical and optical industries, and the United States in financial counseling and medical industries and services. This is indicative of the strategic orientation adopted by these countries for development. The industrial development strategy needs to be knowledge-based and consistent with the requirements of the global market; meanwhile, it has to emphasize market-oriented innovation and technology globalization [16]. The nature of demand impinges upon the goods and services required by an industry. National demand conditions play an essential role in the success or failure of the industry in global markets. The most critical effect of domestic demand on competitive advantage is manifested through a mix of domestic buyers' needs, elevating their capacity for learning and innovation [18].

Supporting industries as well as industries involved in global competition are useful in different ways for the access of enterprises to competitive advantage. Industries such as manufacturing parts, casting, blacksmithing, electrical and electronics industries, and manufacturing engineering comprise an essential part of the external value chain in the automotive industry. The existence of globally competitive industries provides oppor-tunities for the development of information cycles and technical interactions; cultural similarities among competitors accelerate such interactions. Relevant industries also help to identify new opportunities [19].

Recent research on marketing points to the attention specifically paid to emotions when it comes to the consumer-brand relationships. In the past decade, the concept of love was confirmed by marketing research. In the consumers' viewpoint, such an emotion may occur when it is time to love a position or brand. 
Based on the pattern of relationships and the perception that consumers can attribute human characteristics to brands, the scientific community has started to emphasize the concept of love and dependency [20]. John Bowlby [21], the pioneer of attachment theory, defined attachment as "an emotion-laden target-specific bond between a person and a specific object". The general use of the term "brand relationship" was introduced in the late 1990s: a state of affiliation with strong positive feelings and high motives created towards the brand and a desire that the brand dominates consumer minds. Emotional affection represents a mental state of the human mind that a strong emotional and cognitive bond connects a brand with a person so that the brand may be considered as the extension of personality [22].

The new topic of brand popularity has turned into one of the most critical subjects in the market and consumer research in recent years. Consumer research takes love for the brand as one of the main elements of consumer relations with the brand. The critical point is that the concept of love as a great passion will not necessarily relate to brand love or popularity for the consumer [11].

While consumer loyalty is translated into company's growth, yet the foundations of consumer loyalty remain a challenge for many companies. A research study in 1980, providing a new method called the experience method, showed that consump-tion is an experience which includes enthusiasm and a range of emotional reactions [23]. Consumer satisfaction can be defined as the customer's achievement of a previouslyforeseen goal i.e., the mental image of the consumer of the goods and services. This occurs when expectations equal perceptions. Thus, it is more than the expectations of the customers, which need to be taken into account. The key to satisfying consumers is the provision of services exceeding in quality the customer expectations [24]. When a consumer becomes emotionally dependent on a brand, he is most likely satisfied with it. Studies on Harley-Davidson motorcycles indicate that brand satisfaction should be long enough if it is to be considered as emotional attachment or love for the brand [23].

The brand name usually consists of the name, the term, the symbol, and the design or a combination of these elements, used to introduce the products and services of vendors or a group of vendors and to distinguish them from the products and services of rival companies. Different individuals make different evaluations of similar beliefs due to various motivations, personalities, past experiences, reference groups, and distinct physical conditions [19]. The impact of an individual's brand attitude is evident in Clare's explanation, saying that the positive attitudes of consumers towards a brand may lead to the consumers' affection for it. The consumer may even feel that he has a kind of bond with the other consumers of the same brand [20].

For a long time, brand awareness was key to brand management. In a compre-hensive research study, Franz-Rudolf et al. proved that knowledge on brand causes emotional bonds through impacting cus-tomer satisfaction, brand image, and trust [24].

Brand loyalty is the ultimate goal of any company. The customer's priority or preference for buying a particular brand on the shelf is brand loyalty. Initially, customers make a test purchase. Later, in case of being satisfied, they repeat the purchase, as they are now familiar with the product and believe in its safety. In this regard, loyalty has always been reported as the observed behavior [14].

The likelihood of consumers' making strong affiliations with the brand is significant for loyalty research. Based on the dependency theory in psychology, the degree of emotional attachment to an object predicts the nature of the interactions between the person and the object [9].

Additional payment on the brand is defined as the sum of funds the consumers are willing to pay on their desirable brand as against other related brands. This could be either positive or negative. Economists take the additional payment on the brand as an exceptional price. Therefore, an extra payment is a measure of the amount a person allocates for brand experience or consumption based on the monetary unit [14]. Chaudhuri and Holbrook [25] provide an operational definition of brand equity as an extra payment on a specific brand in a range of product classifications and conclude that brands with higher attitudinal loyalty lead to a higher relative price. Keller [26] has shown that consumers with strong and favorable attitudes towards the brand should be more willing to pay higher prices. If a person enjoys brand attachment and love, he will have a more tendency to pay a higher price for that brand. The amount consumers are willing to pay on a brand depends on the degree of emotional dependence they feel [19].

\section{RESEARCH METHODOLOGY}

In order to accurately guide the path of the analysis, 2 hypotheses were developed based on the findings of relevant studies.

\section{H1. Advertising affects Samsung Com-pany's competitive advantage}

\section{H2. Advertising affects Samsung Com-pany's brand popularity}

Accordingly, the appropriate conceptual model was developed for the better understanding of the effect of advertising on competitive advantage and brand popularity of Samsung Company (Figure 1). To test the 
hypotheses, the field research method of data collection was applied, using a questionnaire. This research study is classified as applied in terms of purpose, descriptive in terms of method, and survey in terms of time and duration. In terms of the design and method of implementation, it is categorized as a correlational and survey research as the researcher has used an inferential statistics method to examine the effects of variables on each other. Since this research study can be useful for the better understanding of the consumer behavior in terms of purchase from electronics manufacturing companies, it is also classified as applieddevelopmental. As the present study does not deal with the data associated with a specific period, it may not be considered cross-sectional.

\section{Data Collection Instruments}

To collect the required data, a researcher-made questionnaire was used. Questionnaire items were extracted through a review of previous relevant studies and gathering of local and foreign scientific articles. Benefiting from the guidance and comments of a supervisor and other experts, the questionnaire was prepared based on the five-point Likert-type scale (strongly disagree, disagree, neither agree nor disagree, agree, and strongly agree) to be distributed among respondents. The questionnaire contained 57 items, 21 of which were related to advertising, 18 were concerned with competitive advantage, and the remaining 18 dealt with brand popularity. Table 1 displays the symbols for variables and components as well as the number of questions.

$$
\begin{aligned}
& \alpha=\frac{k}{k-1}\left(1-\frac{\sum_{i=1}^{k} S_{i}^{2}}{\sigma^{2}}\right) \\
& \alpha=\frac{k \bar{C}}{\bar{V}+(k-1) \bar{C}}
\end{aligned}
$$

Where $\mathrm{K}$ is the number of questions, $S_{i}^{2}$ is the variance of question i, $\sigma^{2}$ is the variance of all questions, $\bar{C}$ is the average covariance of questions, and $\bar{V}$ is the average variance of questions.

In this research study, Cronbach's alpha was measured using the SPSS software for variables of advertising (raising awareness, creating a positive attitude and identity, positioning the product in the market, maintaining relationships, persuasion, and dealing with competitors), competitive advantage (environmental capabilities, national infrastructure, the country's development strategy, national demand

\section{Validity of Data Collection Instruments}

To assess the validity of the measure, the component extraction procedure was used, abstracted from the previously conducted research and customized based on expert opinions and the preliminary sample. Accordingly, the evaluation of the two properties of content validity and measurement scale has been done on a qualitative basis. The questionnaire enjoys three content validity criteria as the components of the measured variables are extracted from relevant research studies and the members of the statistical sample understand the questionnaire constructs accurately. The designed questionnaire was submitted to 10 professors and experts as a pre-test. Upon identifying the loopholes and applying necessary modifications, the researcher gave the questionnaire to 30 members of the preliminary statistical population, thereby confirming the relevance of the questions to the statistical population under study. In the last stage, the final version of the questionnaire was prepared.

\section{Reliability of Data Collection Instruments}

One of the most common measures to assess the reliability of a questionnaire is Cronbach's alpha, developed by Lee Cronbach in 1951. A measure is said to have high reliability if it produces similar results under consistent conditions. Cronbach's alpha indicates the degree to which a set of items measures a single unidimensional latent construct. The most commonly used scale in social research is the Likert scale, based on the assumption that the items have the same weights. Thus, scores will be given to each item from 1 to 5 , the sum of which will indicate the tendency of each person. Cronbach's alpha is generally calculated using one of the following relations [23].

conditions, related industries and suppliers, and organizational capabilities), and brand popularity (brand history, consumer satisfaction, consumer attitude, consumer knowledge, consumer loyalty, and additional payment) whose results are presented in Table 2. The findings indicate that the value of Cronbach's alpha for each of the variables is higher than 0.7 , indicating acceptable reliability.

\section{Statistical Population and Sample}

The statistical population in this study includes the managers in the dealerships of Samsung Company in Tehran. Cochran's formula was used to calculate the sample size in this study as follows [17]: 


$$
n=\frac{N t^{2} p q}{\varepsilon^{2}(N-1)+t^{2} p q}
$$

where $\mathrm{n}$ is the minimum sample size, $\mathrm{N}$ is the size of the statistical population, $t$ is the value of the standard variable corresponding to a confidence level of $\alpha-1$ considered at $1.96, \varepsilon$ is the allowed error rate equivalent to $0.05, \mathrm{p}$ is an estimation of the ratio of variable attribute, and q equals $\mathrm{p}-1$.

In this study, the statistical population consists of 1,000 people, 278 of whom were randomly selected as the statistical sample using Cochran's formula. The demographic characteristics of the statistical sample are depicted in Table 3.

\section{RESULTS}

The output of the statistical software regarding the normality of the distribution of advertising, competitive advantage, and brand popularity variables showed that at a significance level of 5 percent, the argument is rejected and the data have a normal distribution. The findings of the first-order confirmatory factor analysis indicated that all questions had a factor loading of more than 0.3. However, the significance levels of questions 12,33 , and 45 were less than 1.96 . Therefore, the $12^{\text {th }}, 33^{\text {rd }}$, and $45^{\text {th }}$ questions were omitted from the measurement model for advertising, competitive advantage, and brand pop-ularity components, respectively, while the remaining questions were considered for the structural equation model.

At the confidence level of 95 percent, there was found a positive and direct relationship between advertising and competitive advantage in Samsung Company. Meanwhile, there proved to be a positive and direct relationship between advertising and brand popularity.

Table-1: Symbols for Variables and Components

\begin{tabular}{|l|l|l|l|}
\hline Variable / Component & Symbol & Number of items & Question numbers \\
\hline Advertising & T & $\mathbf{2 1}$ & $\mathbf{1 - 2 1}$ \\
\hline Raising awareness & T1 & 3 & $1-3$ \\
\hline Creating a positive attitude & T2 & 3 & $4-6$ \\
\hline Creating positive identity & T3 & 3 & $7-9$ \\
\hline Positioning the product in the market & T4 & 3 & $10-12$ \\
\hline Maintaining relationships & T5 & 3 & $13-15$ \\
\hline Persuasion & T6 & 3 & $16-18$ \\
\hline Dealing with competitors & T7 & 3 & $19-21$ \\
\hline Competitive advantage & MR & $\mathbf{1 8}$ & $\mathbf{2 2 - 3 9}$ \\
\hline Environmental capabilities & MR1 & 3 & $22-24$ \\
\hline National infrastructure & MR2 & 3 & $25-27$ \\
\hline The country's development strategy & MR3 & 3 & $28-30$ \\
\hline National demand conditions & MR4 & 3 & $31-33$ \\
\hline Related industries and suppliers & MR5 & 3 & $34-36$ \\
\hline Organizational capabilities & MR6 & 3 & $37-39$ \\
\hline Brand popularity & MB & $\mathbf{1 8}$ & $\mathbf{4 0 - 5 7}$ \\
\hline Brand history & MB1 & 3 & $40-42$ \\
\hline Consumer satisfaction & MB2 & 3 & $43-45$ \\
\hline Consumer attitudes & MB3 & 3 & $46-48$ \\
\hline Consumer knowledge & MB4 & 3 & $49-51$ \\
\hline Consumer loyalty & MB5 & 3 & $52-54$ \\
\hline Additional payment & MB6 & 3 & $55-57$ \\
\hline
\end{tabular}

Table-2: Value of Cronbach's Alpha for Research Variables

\begin{tabular}{|r|c|c|}
\hline Variable & Component & Test coefficient \\
\hline Advertising & Raising awareness & 0.858 \\
\cline { 2 - 3 } & Creating a positive attitude & 0.913 \\
\cline { 2 - 3 } & Creating positive identity & 0.802 \\
\cline { 2 - 3 } & Positioning the product in the market & 0.792 \\
\cline { 2 - 3 } & Maintaining relationships & 0.864 \\
\cline { 2 - 3 } & Persuasion & 0.892 \\
\cline { 2 - 3 } & Dealing with competitors & 0.894 \\
\hline
\end{tabular}




\begin{tabular}{|c|c|c|}
\hline Competitive advantage & Environmental capabilities & 0.873 \\
\cline { 2 - 3 } & National infrastructure & 0.853 \\
\cline { 2 - 3 } & The country's development strategy & 0.787 \\
\cline { 2 - 3 } & National demand conditions & 0.810 \\
\cline { 2 - 3 } & Related industries and suppliers & 0.789 \\
\cline { 2 - 3 } & Organizational capabilities & 0.870 \\
\hline Brand popularity & Brand history & 0.863 \\
\cline { 2 - 3 } & Consumer satisfaction & 0.792 \\
\cline { 2 - 3 } & Consumer attitudes & 0.812 \\
\cline { 2 - 3 } & Consumer knowledge & 0.818 \\
\cline { 2 - 3 } & Consumer loyalty & 0.844 \\
\cline { 2 - 3 } & Additional payment & 0.876 \\
\hline
\end{tabular}

Table-3: Distribution and Frequency Percentage of Variables Related to Demographic Variables

\begin{tabular}{|c|c|c|c|}
\hline \multirow{2}{*}{\multicolumn{2}{|c|}{ Variable }} & \multicolumn{2}{|c|}{ Managers of Samsung Company's Dealerships in Tehran } \\
\hline & & Frequency & Frequency percentage \\
\hline \multirow[t]{2}{*}{ Sex } & Men & 165 & 59.35 \\
\hline & Women & 113 & 40.65 \\
\hline \multirow[t]{3}{*}{ Age } & $25-30$ & 62 & 22.30 \\
\hline & $31-35$ & 127 & 45.68 \\
\hline & $36-40$ & 89 & 32.01 \\
\hline \multirow[t]{3}{*}{ Education } & Associate's degree & 23 & 8.27 \\
\hline & Bachelor's degree & 204 & 73.38 \\
\hline & Master's degree & 51 & 18.35 \\
\hline \multirow[t]{4}{*}{ Work experience } & 1 to 5 years & 43 & 15.47 \\
\hline & 6 to 10 years & 62 & 22.30 \\
\hline & 11 to 15 years & 146 & 52.52 \\
\hline & 16 to 20 years & 27 & 9.71 \\
\hline \multicolumn{2}{|c|}{ Total } & 278 & 100 \\
\hline
\end{tabular}

Table-4: The Results of the Kolmogorov-Smirnov Test

\begin{tabular}{|c|c|c|c|}
\hline Variable & Component & Test coefficient & Significance level \\
\hline \multirow{4}{*}{ Advertising } & Raising awareness & 2.927 & 0.072 \\
\cline { 2 - 4 } & Creating a positive attitude & 2.650 & 0.072 \\
\cline { 2 - 4 } & Creating positive identity & 2.169 & 0.059 \\
\cline { 2 - 4 } & Positioning the product in the market & 3.053 & 0.062 \\
\cline { 2 - 4 } & Maintaining relationships & 2.281 & 0.058 \\
\cline { 2 - 4 } & Persuasion & 2.586 & 0.070 \\
\cline { 2 - 4 } & Dealing with competitors & 2.687 & 0.055 \\
\hline Competitive advantage & Environmental capabilities & 2.151 & 0.066 \\
\cline { 2 - 4 } & National infrastructure & 2.062 & 0.054 \\
\cline { 2 - 4 } & The country's development strategy & 2.958 & 0.068 \\
\cline { 2 - 4 } & National demand conditions & 3.110 & 0.077 \\
\cline { 2 - 4 } & Related industries and suppliers & 3.022 & 0.074 \\
\cline { 2 - 4 } & Organizational capabilities & 2.526 & 0.066 \\
\hline Brand popularity & Brand history & 2.474 & 0.070 \\
\cline { 2 - 4 } & Consumer satisfaction & 2.971 & 0.076 \\
\cline { 2 - 4 } & Consumer attitudes & 2.659 & 0.062 \\
\cline { 2 - 4 } & Consumer knowledge & 2.614 & 0.079 \\
\cline { 2 - 4 } & Consumer loyalty & 2.600 & 0.060 \\
\cline { 2 - 4 } & Additional payment & 3.043 & 0.065 \\
\cline { 2 - 4 } & & & \\
\hline
\end{tabular}

Table-5: Appropriate Fitting of the Model Based on the LISERL Software

\begin{tabular}{|r|c|c|c|c|c|c|}
\hline Measurement Models & Chi-square & Df & P-value & RMSEA & GFI & AGFI \\
\hline Advertising & 381.7 & 113 & 0.000 & 0.073 & 0.93 & 0.92 \\
\hline Competitive advantage & 405.2 & 113 & 0.000 & 0.005 & 0.89 & 0.91 \\
\hline Brand popularity & 311.6 & 113 & 0.000 & 0.12 & 0.95 & 0.92 \\
\hline
\end{tabular}


Table-6: Comparison of the Model Fit Indices with the Allowed Amount

\begin{tabular}{|r|c|c|c|c|}
\hline Indicator & Symbol & Allowed amount & Calculated coefficients & Result \\
\hline Goodness of fit index & GFI & Higher than 0.9 & 0.95 & Good fit \\
\hline Adjusted goodness of fit index & AGFI & Higher than 0.9 & 0.94 & Good fit \\
\hline Standardized root mean square residual indicator & RMR & Close to zero & 0.08 & Good fit \\
\hline Normative fit index & NFI & Higher than 0.9 & 0.98 & Good fit \\
\hline Increased fit index & IFI & Higher than 0.9 & 0.98 & Good fit \\
\hline
\end{tabular}

Table-7: Structural Equation Analysis of the First Hypothesis

\begin{tabular}{|c|c|c|c|c|}
\hline \multicolumn{2}{|c|}{ Path } & Factor loading & Significance level & Result \\
\hline Independent variable & Dependent variable & 0.60 & 2.38 & Accepted \\
\cline { 1 - 2 } Advertising & Competitive advantage & & & \\
\hline
\end{tabular}

Table-8: Structural Equation Analysis of the Second Hypothesis

\begin{tabular}{|c|c|c|c|c|}
\hline \multicolumn{2}{|c|}{ Path } & Factor loading & Significance level & Result \\
\hline Independent variable & Dependent variable & 0.51 & 8.12 & Accepted \\
\cline { 1 - 2 } Advertising & Brand popularity & & & \\
\hline
\end{tabular}

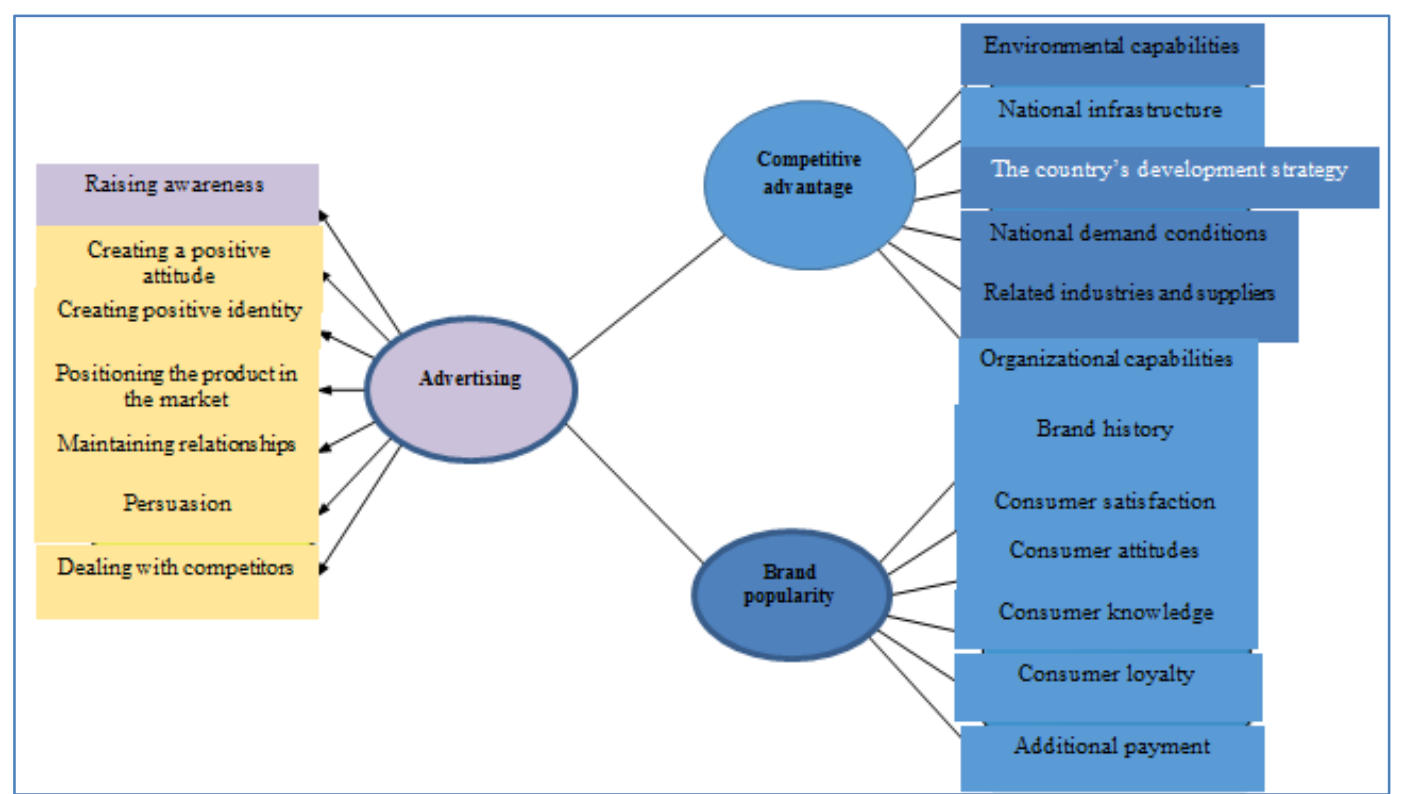

Fig-1: Conceptual Model of A Study on the Role of Advertising on the Competitive Advantage and Brand Popularity of Business Firms (Case Study: Samsung Company)

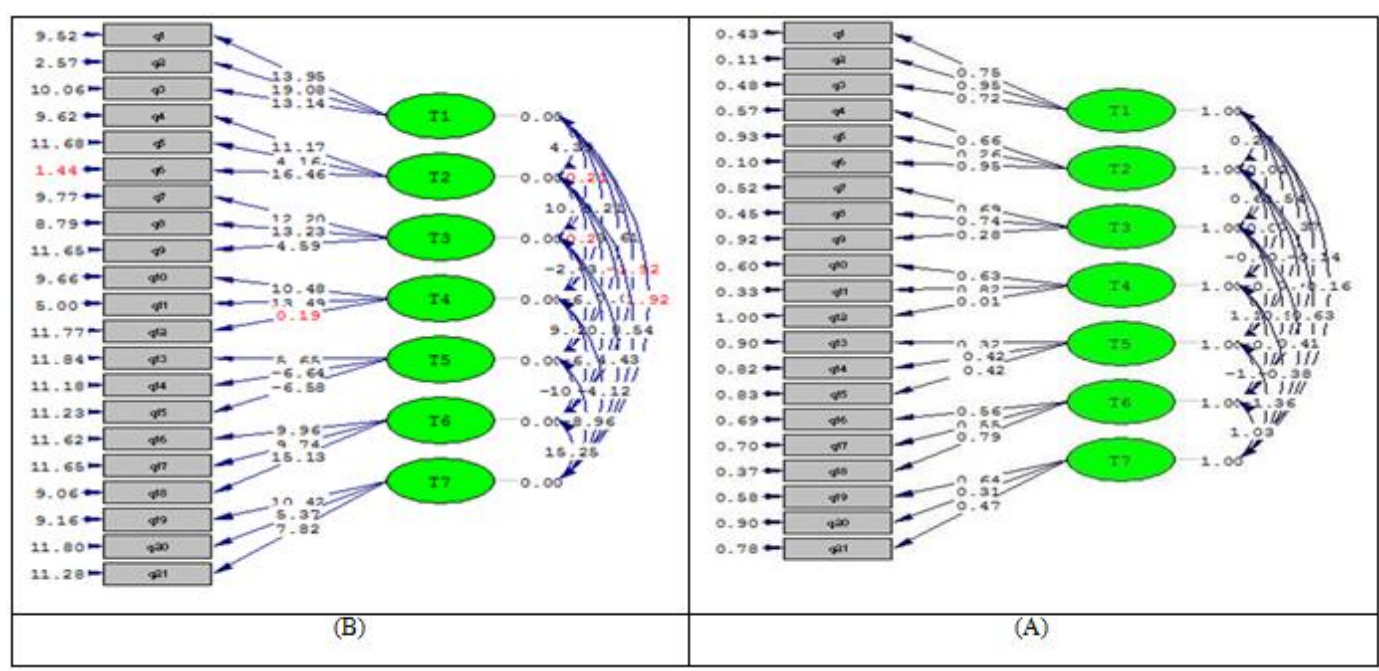

Fig-2: Factor Analysis of Measurement Model for Components of the Advertising Variable in modes (A) standard estimates and (B) significant coefficients 


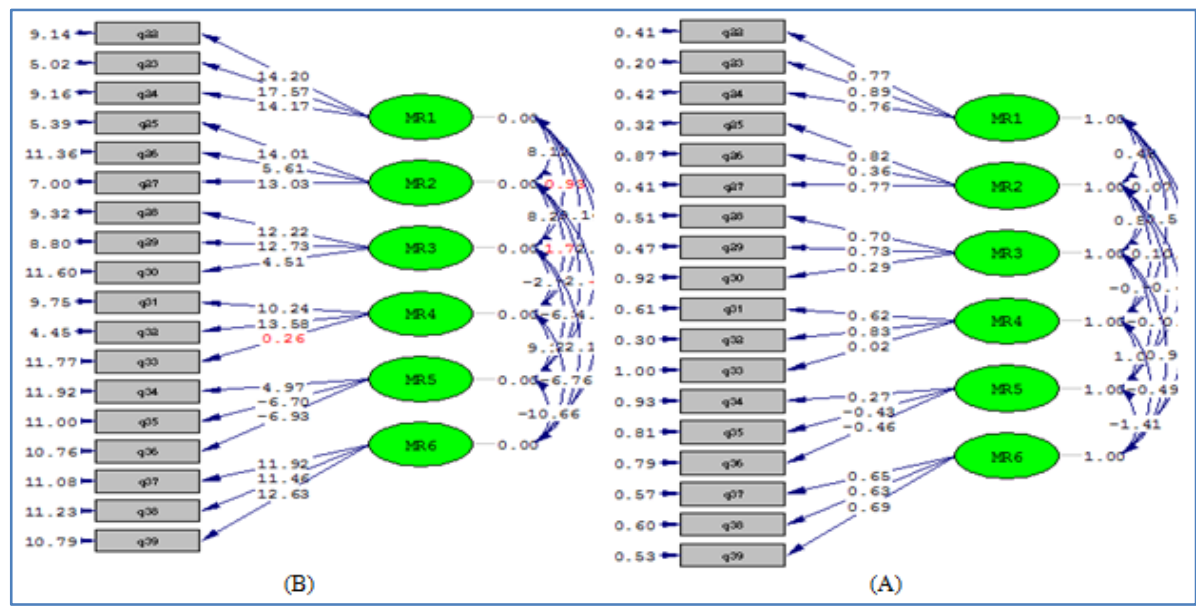

Fig-3: Confirmatory Factor Analysis of Measurement Model for Components of the Competitive Advantage Variable in Modes (A) Standard Estimates and (B) Significant Coefficients

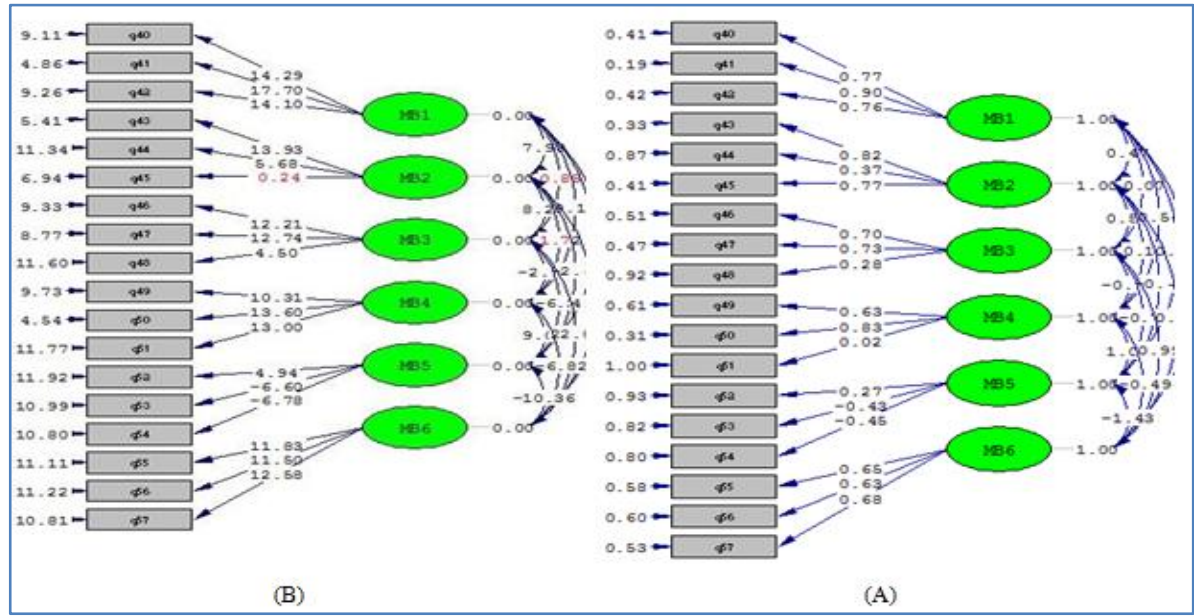

Fig-4: Confirmatory Factor Analysis of Measurement Model for Components of the Brand Popularity Variable in Modes (A) Standard Estimates and (B) Significant Coefficients

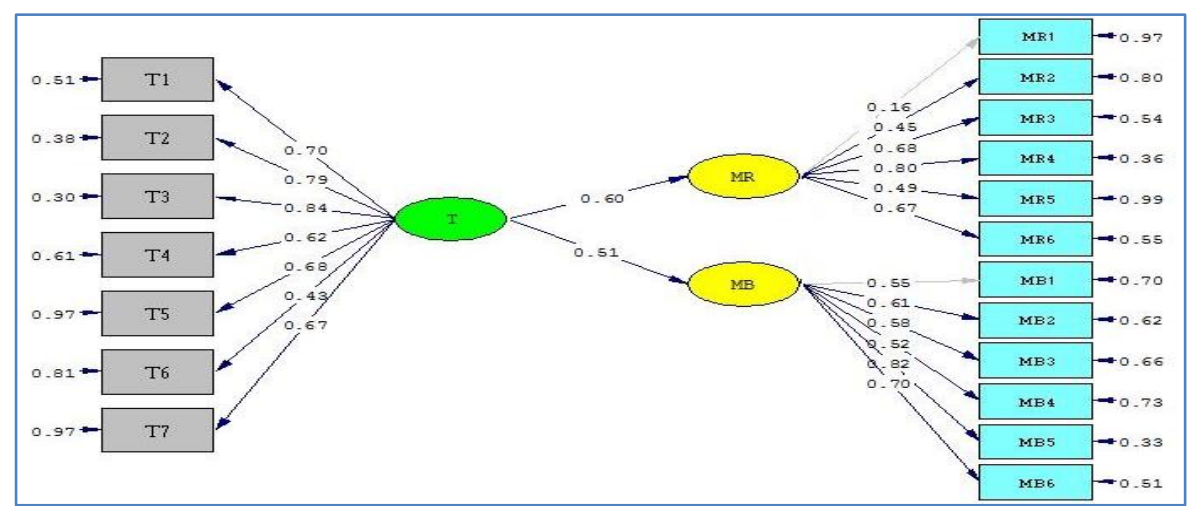

Fig-5: Structural Equation Modeling of Conceptual Model in Standard Mode

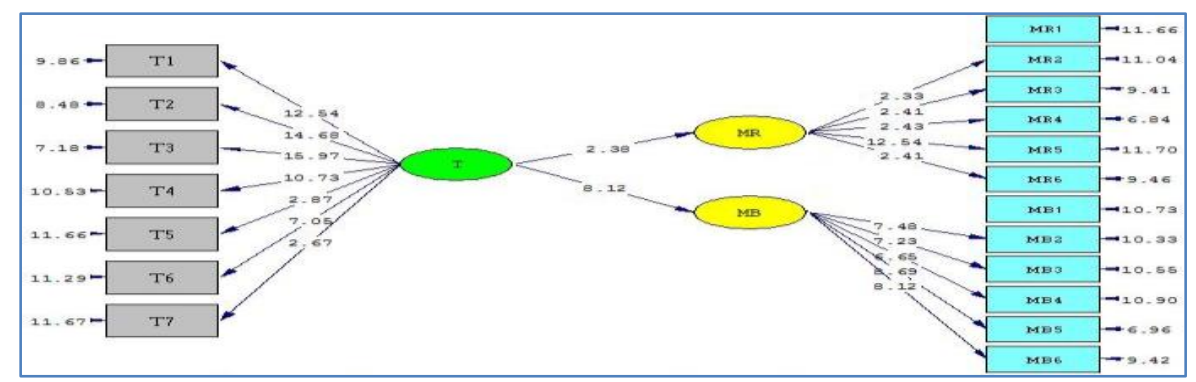

Fig-6: Structural Equation Modeling of Conceptual Model in the Case of Significant Coefficients Mode 


\section{DISCUSSION}

The one-sample Kolmogorov-Smirnov test is used in SPSS software to check whether or not the data set is drawn from a particular distribution. Four distributions are supported, namely normal, uniform, poisson, and exponential. This method is based on the difference between the relative cumulative frequencies of observations with an expected value under the null hypothesis. The null hypothesis states that the selected sample has a normal (poisson, exponential, or uniform) distribution [6]. If the significance level is less than 5 percent, the null hypothesis is rejected i.e., data cannot have a specific distribution such as normal, poisson, exponential, or uniform. The null hypothesis and the argument are presented as follows [14].

Null hypothesis, error larger than 0.05: If the error is larger than 0.05 in the value of the significance coefficient parameter or decision criterion, the null hypothesis is accepted. This means that there is no reason to reject the hypothesis that the desired sample is obtained from the normal distribution. Therefore, the distribution of variable-related data is normal.

Argument, error less than 0.05: If the error is less than 0.05 in the value of the significance coefficient parameter or decision criterion, the argument is accepted. This means that there is no reason to accept the hypothesis that the desired sample is obtained from the normal distribution. Therefore, the distribution of variable-related data is not normal.

To examine the causal relationship among variables, the structural equation modeling or multivariate analysis is used. The appropriate model indicators consist of Chi-squared $\left(\chi^{2}\right)$, Goodness of Fit Index (GFI), and Adjusted Goodness of Fit Index (AGFI). If the amount of $\chi^{2} / d f$ is less than 3 , it is indicative of good model fit. Meanwhile, the closer the AGFI and GFI to one, the better the fit of the model [3]. To reduce variables and consider them as latent, the factor loadings obtained should be more than 0.3. A suitable model should enjoy the following features: the lower the chi-squared test, the better; as this test shows the difference between the data and the model. The less the RMSEA test, the better; as this is the mean square of the model errors [5]. Results of the KolmogorovSmirnov test for variables of this study are presented in Table 4.

To evaluate the hypotheses, the struc-tural equation modeling analysis (Figures 5 and 6) was used, the results of which are presented in Tables 7 and 8 .

\section{Structural Equation Modeling}

Using LISREL software, the structural equation model was calculated in the standard estimation and the case of significance coefficients, as shown in Figures 5 and 6. To determine the model fit, some specific indicators were used, the calculated value of which as compared to the permitted value is presented in Table 6 . The estimated coefficients are good when the structural equation model in Table 6 is placed within the allowable range. If the calculated coefficients are outside the permissible scope, this indicates poor fit. The comparison of the columns of the calculated coefficients with the allowed range column shows that the model fit indices are suitable. After examining the fit indices, the hypotheses are evaluated.

Based on the analysis of the structural equations, the standard coefficient between the two latent variables of advertising and competitive advantage was equal to 0.60 (Figure 5), and according to the significance level (2.38) which is larger than 1.96 (Figure 6), the null hypothesis is rejected at the significance level of 5 percent and the argument is confirmed.

Accordingly, for a one-unit increase in advertising, Samsung Company's com-petitive advantage is increased by as much as 0.60 units (Table 7). Moreover, the standard coefficient between the two latent variables of advertising and brand popularity is equal to 0.51 (Figure 5), and according to the significance level (8.12) which is larger than 1.96 (Figure 6), the null hypothesis is rejected at the significance level of 5 percent and the argument is confirmed. Accordingly, for a one-unit increase in advertising, Samsung Company's brand popularity is increased by as much as 0.51 units (Table 8 ).

To evaluate the questionnaire's reliability, Cronbach's alpha was used. Based on definition, with the rise in the positive correlation among questions, Cronbach's alpha will increase and vice versa; with the increase in the average variance of questions, Cronbach's alpha will decrease; the increase in the number of questions will have either a positive or a negative impact on Cronbach's alpha; and the increase in the sample size will reduce the average variance of questions and thus improve Cronbach's alpha. The closer Cronbach's alpha to 1 , the higher the internal consistency among questions. As a result, questions will be more homo-geneous. Cronbach has suggested that the coefficient of 45 percent is low, 75 percent is moderate and acceptable, and 95 percent is high. If the alpha value is small, the questions must be checked to see which ones could be eliminated so that the coefficient may increase [14].

Before entering the stage of hypothesis testing and evaluating the structural model, it is necessary to ensure the accuracy of the measurement models of every single research area. This takes place through the confirmatory factor analysis aimed at confirming the theoretical models and ensuring the fitness of data in the theoretical models. Therefore, measure-ment models of advertising, competitive advantage, and brand 
popularity are presented, conducted by structural equation modeling. Subsequently, independent and dependent variables are evaluated using the LISREL software.

\section{Measurement Models}

The variable of advertising is independent, consisting of raising awareness, creating a positive attitude and identity, positioning the product in the market, maintaining relationships, persuasion, and dealing with competitor's components. Using the LISREL software, the confirmatory factor analysis model related to the components of this variable in the standard estimation and the case of significance coefficients is displayed in Figure 2. An observable variable will well evaluate the latent variable in case its factor loadings (figures on the arrows of the confirmatory factor analysis model in standard estimation mode) are more than 0.3 and the significance levels (figures on the arrows of the confirmatory factor analysis model in the case of significance coefficients) are higher than 1.96 or lower than -1.96 .

The variable of competitive advantage is dependent, consisting of environmental capabilities, national infrastructure, the country's development strategy, national demand conditions, related industries and suppliers, and organizational capabilities components (Figure 3). The variable of brand popularity is dependent, consisting of brand history, consumer satisfaction, consumer attitude, consumer knowledge, consumer loyalty, and additional payment components (Figure 4).

The fit criteria of the measurement models of the variables of advertising, competitive advantage, and brand popularity are presented in Table 5. Given that the expressed indices have a favorable condition, the measurement models for these variables are approved. Upon evaluating the measurement models, the structural equation model will be addressed.

\section{CONCLUSION}

The purpose of this study was to review the role of advertising in competitive advantage and brand popularity of case study: Samsung Company in Tehran. To this end, 278 managers of Samsung Company dealerships in Tehran were considered as the statistical sample. To collect data, a researcher-made questionnaire, consisting of 57 items, was used, whose face and content validity criteria were approved by 30 experts. The questionnaire's reliability was calculated through a preliminary test with 30 subjects at the significance level of more than 0.7 for all the examined variables, which was acceptable. For data analysis, descriptive statistics method in the SPSS software, version 24 , and the inferential statistics method via the structural equation modeling in the LISREL software, version 8 , were used.
The output of the statistical software regarding the distribution normality of advertising, competitive advantage, and brand popularity showed that at the significance level of 5 percent, the argument was rejected and the data had a normal distribution.

After checking the factor loadings and the significance level for the measurement models of advertising, competitive advantage, and brand popularity, the evaluation of model fit criteria was addressed and the fit criteria of the measurement models were calculated. Given that the expressed indices had a favorable condition, the measurement models for these variables were approved. After evaluating the measurement models, the structural equation modeling was addressed. Using LISREL software, the structural equation model was calculated in the standard estimation and the case of significance coefficients. To determine the model fit, some certain indicators were used, the calculated value of which compared to the permitted value was presented. A comparison of the columns of the calculated coefficients with the allowed range column showed that the model fit indices were suitable. After examining the model fit, the hypothesis was evaluated.

Regarding H1, positing that advertising affects competitive advantage in Samsung Company, there was a positive and direct relationship between advertising and competitive advantage in Samsung Company at the confidence level of 95 percent. Meanwhile, in terms of $\mathrm{H} 2$, positing that advertising affects brand popularity in Samsung Company, there was a positive and direct relationship between advertising and brand popularity in Samsung Company at the confidence level of 95 percent.

\section{REFERENCES}

1. Hsu, C. L., \& Chen, M. C. (2018). How gamification marketing activities motivate desirable consumer behaviors: Focusing on the role of brand love. Computers in human behavior, 88, 121-133.

2. Sakas, D. P., Dimitrios, N. K., \& Kavoura, A. (2015). The Development of Facebook's Competitive Advantage for Brand Awareness. Procedia Economics and Finance, 24, 589-597.

3. Anggraeni, A. (2015). Effects of brand love, personality and image on word of mouth; the case of local fashion brands among young consumers. Procedia-Social and Behavioral Sciences, 211, 442-447.

4. Drennan, J., Bianchi, C., Cacho-Elizondo, S., Louriero, S., Guibert, N., \& Proud, W. (2015). Examining the role of wine brand love on brand loyalty: A multi-country comparison. International Journal of Hospitality Management, 49, 47-55.

5. Kang, A. (2015). Brand love-moving beyond loyalty an empirical investigation of perceived 
brand love of Indian consumer. Arab Economic and Business Journal, 10(2), 90-101.

6. Giovanis, A. N., \& Athanasopoulou, P. (2018). Consumer-brand relationships and brand loyalty in technology-mediated services. Journal of Retailing and Consumer Services, 40, 287-294.

7. Liu, Y., \& Mantecon, T. (2017). Is sustainable competitive advantage an advantage for stock investors?. The Quarterly Review of Economics and Finance, 63, 299-314.

8. Singjai, K., Winata, L., \& Kummer, T. F. (2018). Green initiatives and their competitive advantage for the hotel industry in developing countries. International Journal of Hospitality Management, 75, 131-143.

9. Maury, B. (2018). Sustainable competitive advantage and profitability persistence: Sources versus outcomes for assessing advantage. Journal of Business Research, 84, 100-113.

10. Ranjith, V. K. (2016). Business models and competitive advantage. Procedia Economics and Finance, 37, 203-207.

11. Rui, H., Zhang, M., \& Shipman, A. (2017). Chinese expatriate management in emerging markets: A competitive advantage perspective. Journal of International Management, 23(2), 124-138.

12. Gellweiler, C. (2017). Bridging IT requirements to competitive advantage: The concept of IT value planning. Procedia computer science, 121, 145151.

13. Cheraghalizadeh, R., \& Tümer, M. (2017). The effect of applied resources on competitive advantage in hotels: Mediation and moderation analysis. Journal of Hospitality and Tourism Management, 31, 265-272.

14. Gunasekaran, A., Subramanian, N., \& Papadopoulos, T. (2017). Information technology for competitive advantage within logistics and supply chains: A review. Transportation Research Part E: Logistics and Transportation Review, 99, 14-33.

15. Mpinganjira, M., \& Maduku, D. K. (2019). Ethics of mobile behavioral advertising: Antecedents and outcomes of perceived ethical value of advertised brands. Journal of Business Research, 95, 464-478.
16. Pnevmatikos, N., Vardar, B., \& Zaccour, G. (2018). When should a retailer invest in brand advertising?. European Journal of Operational Research, 267(2), 754-764.

17. Bell, R., \& Buchner, A. (2018). Positive effects of disruptive advertising on consumer preferences. Journal of Interactive Marketing, 41, $1-13$.

18. Cartwright, J., McCormick, H., \& Warnaby, G. (2016). Consumers' emotional responses to the Christmas TV advertising of four retail brands. Journal of Retailing and Consumer Services, 29, 82-91.

19. Zenetti, G., \& Klapper, D. (2016). Advertising effects under consumer heterogeneity-the moderating role of brand experience, advertising recall and attitude. Journal of Retailing, 92(3), 352-372.

20. Amrouche, N., \& Yan, R. (2017). National brand's local advertising and wholesale-price incentive under prior versus no prior information. Industrial marketing management, 64, 161-174.

21. Bowlby, J. (1979). The making and breaking of affectional bonds. London. Tavistock Publications. Boyd, J. H, \& Weissman, MM (1981). Epidemiology of affective disorders: A reexamination of future directions. Archives of General Psychiatry, 38, 1039-1046.

22. Jayawardhana, J. (2013). Direct-to-consumer advertising and consumer welfare. International Journal of Industrial Organization, 31(2), 164-180.

23. Liao, Z. (2016). Temporal cognition, environmental innovation, and the competitive advantage of enterprises. Journal of cleaner production, 135, 1045-1053.

24. Merchant, A., \& Rose, G. M. (2013). Effects of advertising-evoked vicarious nostalgia on brand heritage. Journal of Business Research,66(12), 2619-2625.

25. Chaudhuri, A., \& Holbrook, M. B. (2001). The chain of effects from brand trust and brand affect to brand performance: the role of brand loyalty. Journal of marketing, 65(2), 81-93.

26. Keller, K. L. (1993). Conceptualizing, measuring, and managing customer-based brand equity. Journal of marketing, 57(1), 1-22. 